\title{
LHX3 deficiency presenting in the United States with severe developmental delay in a child of Syrian refugee parents
}

\author{
Susan Ahern', Mark Daniels² and Amrit Bhangoo² \\ 'Division of Endocrinology, UCLA School of Medicine, Ventura, California, USA and 2Division of Pediatric \\ Endocrinology, Children's Hospital of Orange County, Orange, California, USA
}

\section{Summary}

In this case report, we present a novel mutation in Lim-homeodomain (LIM-HD) transcription factor, LHX3, manifesting as combined pituitary hormone deficiency (CPHD). This female patient was originally diagnosed in Egypt during infancy with Diamond Blackfan Anemia (DBA) requiring several blood transfusions. Around 10 months of age, she was diagnosed and treated for central hypothyroidism. It was not until she came to the United States around two-and-a-half years of age that she was diagnosed and treated for growth hormone deficiency. Her response to growth hormone replacement on linear growth and muscle tone were impressive. She still suffers from severe global development delay likely due to delay in treatment of congenital central hypothyroidism followed by poor access to reliable thyroid medications. Her diagnosis of DBA was not confirmed after genetic testing in the United States and her hemoglobin normalized with hormone replacement therapies. We will review the patient's clinical course as well as a review of $L H X 3$ mutations and the associated phenotype.

\section{Learning points:}

- Describe an unusual presentation of undertreated pituitary hormone deficiencies in early life

- Combined pituitary hormone deficiency due to a novel mutation in pituitary transcription factor, LHX3

- Describe the clinical phenotype of combined pituitary hormone deficiency due to LHX3 mutations

\section{Background}

In humans, the pituitary gland is composed of two major parts; the anterior and posterior lobes. The posterior pituitary arises during development from the ventral diencephalon and secretes the hormones oxytocin and vasopressin. The anterior pituitary gland is derived from Rathke's pouch, an outgrowth of the oral ectoderm. It contains five hormone-secreting cell types: somatotrophs, lactotrophs, thyrotrophs, gonadotrophs and corticotrophs, which secrete growth hormone (GH), prolactin (PRL), thyroid-stimulating hormone (TSH), the gonadotropin hormones (luteinizing hormone (LH) and folliclestimulating hormone (FSH)) and adrenocorticotrophic hormone $(\mathrm{ACTH})$, respectively. Following early inductive events, the actions of specific transcription factors are important for the determination and differentiation of these specialized cell types. Several Lim-homeodomain (LIM-HD) class transcription factors, including LHX3, play critical roles in pituitary and nervous system development (1). Mutations in the genes encoding these transcription factors cause complex hormone deficiency diseases in humans and animal models. This phenotype is referred to as combined pituitary hormone deficiency (CPHD).

In mice, LHX3 gene is expressed in the embryonic nervous system and in the developing and mature 
pituitary (2). A homozygous deletion of LHX3 gene in mice results in incomplete pituitary development, aberrant motor neuron specification and perinatal death. In these animals, some ACTH is detectable, indicating at least partial corticotroph cell function, but the characteristic hormones of the other anterior pituitary cells are not found, indicating that LHX3 is required for development of four of the five specialized cell types (3). Molecular studies have demonstrated that LHX3 can activate pituitary expressed genes, such as those encoding the alpha-glycoprotein subunit ( $\alpha \mathrm{GSU})$, PRL, FSHB, TSHB, the gonadotropin releasing hormone (GnRH) receptor, Pit-1 transcription factor and lead to later onset of ACTH deficiency $(3,4,5)$. LHX3 is also important for development of both the inner ear and the anterior pituitary in human embryonic development. Some of the extra-pituitary manifestations of LHX3 mutation are sensorineural hearing loss and limited neck rotation.

Identifying a genetic etiology for CHPD is even more rare than the disease itself. It is estimated that the worldwide mutation frequency for CHPD is $12.4 \%$, ranging from $11.2 \%$ of sporadic and up to $63 \%$ of familial cases (6). Here, we describe a case of a 3.5-year-old girl with CPHD who was found to have a novel mutation in LIM-HD transcription factor, LHX3. Furthermore, this case is an impressive example of extreme growth and developmental delay from poorly treated CPHD, which is now rarely seen in the United States. Documentation of novel mutations from different regions of the world and descriptions of associated phenotypes will assist clinicians with management, prognosis and counseling and adds to global knowledge of CHPD.

\section{Case presentation}

Our patient is now a 4-year-old girl who was born in Egypt to Syrian refugee parents. During pregnancy, her mother moved from Syria to Egypt to take asylum. The family immigrated to southern California from Egypt when the patient was 2.5 years of age. She has a biological sister who is healthy and normal in growth and development. Her parents are non-consanguineous. Upon arrival into the United States, she presented to CHOC Children's with failure to gain weight, poor linear growth, constipation, poorly treated hypothyroidism, possible central adrenal insufficiency and a prior diagnosis of DBA.

On initial examination, at 2.5 years of age, she had marked developmental delay. Motor development was limited to lying supine in bed, her anterior fontanelle was open and there was sparse dark hair covering the entire scalp with low anterior and normal posterior hairline. There was mild right-sided positional plagiocephaly, triangular-shaped face prominent forehead, midfacial hypoplasia, mild hypertelorism and blue sclerae. Palpebral fissures were wide and downward slanting. In addition, she had macroglossia, hypotonia and protuberant abdomen. At the time of the admission, her height SDS was at -7.98 and the weight was at -9.01 SDS equivalent to overall stature was equivalent to a 3-to-4-month-old baby. MRI revealed hypoplasia of the anterior pituitary with an intact posterior bright spot. Chromosomal microarray showed a normal female microarray result of $46, \mathrm{XX}$.

Her previous medical records documented growth retardation and failure to thrive in early life. Around 10 months of age, she was diagnosed and treated for central hypothyroidism when low TSH and free T4 were detected. Despite treatment with levothyroxine $50 \mu \mathrm{g}$, brand name Eltroxin, her admission FT4 levels were undetectable. We hypothesize this was due to denatured thyroxine medication. GH deficiency was suspected due to extreme growth failure, frontal bossing, midfacial hypoplasia and mild hypertelorism.

\section{Investigation}

Hormonal evaluation revealed low IGF1 and IGFBP3. A bone age at 3 years 3 months of chronological age was read close to 18 months of bone age. Profound GH deficiency was confirmed. It was not clear, initially, whether she had concomitant central adrenal insufficiency with GH deficiency and central hypothyroidism vs secondary adrenal insufficiency from steroid use as she was taking Prednisolone $0.5 \mathrm{mg}$ three times a day for the treatment of previously diagnosed with DBA at 3 months of age in Egypt. The ACTH1-24 or Cortrosyn stimulation showed a low response to the low-dose $1 \mu \mathrm{g}$ Cortrosyn, but robust to the high dose $249 \mu \mathrm{g}$ Cortrosyn at age 2.5 years to 3 years of age (Table 1), consistent with secondary adrenal insufficiency. She had previously required five units of packed red cells every 3 months for presumed DBA. Genetic testing for DBA in the United States was negative. Hemoglobin electrophoresis was unremarkable.

Genetic analysis for evaluation of hypopituitarism was performed and the mutational analysis was positive for homozygous LHX3 mutation, specifically a novel c. $95-2 \mathrm{~A}>\mathrm{G}$ variant. This mutation occurs in the late intronic position, affecting the acceptor splice sites leading to an alteration of the WT acceptor site, most probably affecting splicing. Exome trio was performed on both parents and they were found to be asymptomatic carriers of the same 
Table 1 Hormonal profile of the patient at the time of the first evaluation in the United States. Along with the results of the ACTH1-24 stimulation test. Low dose stimulation test was by using $1 \mu \mathrm{g}$ of ACTH1-24 and high dose was by using ACTH1-24.

\begin{tabular}{lcc}
\hline & Normal range \\
\cline { 1 - 2 } Cortisol, $\mathrm{nmol} / \mathrm{L}$ & $137.93-744.83$ \\
$\mathrm{TSH}, \mu \mathrm{IU} / \mathrm{mL}$ & $0.7-4.17$ \\
Free $\mathrm{T4}, \mathrm{pmol} / \mathrm{L}$ & $11.45-17.63$ \\
Human growth hormon, $\mathrm{\mu g} / \mathrm{L}$ & $\leq 6.0$ \\
$\mathrm{IGFBP3}, \mathrm{mg} / \mathrm{L}$ & $0.8-3.0$ \\
$\mathrm{IGF1}, \mathrm{nmol} / \mathrm{L}$ & $7.3-18.8$ \\
$\mathrm{ACTH}, \mathrm{pg} / \mathrm{mL}$ & $1.3-10.7$ \\
$\mathrm{FSH}, \mathrm{U} / \mathrm{L}$ & $1-4.2$ \\
$\mathrm{LH}, \mathrm{U} / \mathrm{L}$ & $0.02-0.3$ \\
Cortrosyn or ACTH1-24 stimulation test, $\mathrm{nmol} / \mathrm{L}$ & \\
$\quad$ Baseline cortisol & $137.93-744.83$ \\
$\quad$ Cortisol post-low dose & $\geq 496.55$ \\
Cortisol post-high dose & $\geq 496.55$ \\
\hline
\end{tabular}

\begin{tabular}{|c|c|c|c|}
\hline 2 years 6 months & 2 years 7 months & 3 years & 4 years \\
\hline $\begin{array}{l}480.00 \\
0 \\
<5.15 \\
0.113 \\
0.42 \\
6.3 \\
4.7 \\
0.175 \\
0.014\end{array}$ & & & 104.28 \\
\hline $\begin{array}{l}134.34 \\
328.28 \\
747.59\end{array}$ & $\begin{array}{l}117.52 \\
468.97 \\
827.59\end{array}$ & $\begin{array}{r}253.79 \\
386.21 \\
579.31\end{array}$ & \\
\hline
\end{tabular}

c.95-2A>G mutation in the $L H X 3$ gene. This finding is consistent with autosomal recessive CPHD. Other genes, such as, GHR, HESX1, LHX4, OTX2, POU1F1, PROP1, are negative for mutations.

\section{Treatment}

On presentation, she was restarted on levothyroxine $8 \mu \mathrm{g} / \mathrm{kg} /$ day. Prednisolone was changed to an equivalent dose of hydrocortisone; $2.5 \mathrm{mg}$ TID or $23 \mathrm{mg} / \mathrm{m}^{2} /$ day. Subsequently, hydrocortisone was tapered off over 8 days given presumed secondary adrenal insufficiency from exogenous steroids. GH therapy was initiated at $0.25 \mathrm{mg}$ SQ daily $(0.3 \mathrm{mg} / \mathrm{kg} /$ week $)$ and maintained for 1 year. Supplemental enteral nutrition initiated as well.

\section{Outcome and follow-up}

Initiation of $\mathrm{GH}$ and supplemental enteral nutrition improved weight gain from -9.01 SD to -1.17 SDS approximately over 12 months. As a result of treatment, her overall tone improved significantly, and she was able to tolerate partial nutrition by mouth. The growth velocity ranged from 16 to $31 \mathrm{~cm} /$ year showing catch up growth (Table 2). She had an excellent response to GH growing with the height SD changed from -7.98 to

Table 2 Height SDS and growth velocity after starting growth hormone therapy.

\begin{tabular}{|c|c|c|}
\hline Date & Height SDS & Growth velocity (cm/year) \\
\hline $12 / 14 / 16$ & -7.98 & \\
\hline $1 / 30 / 2017$ & -7.31 & 29.2 \\
\hline $4 / 24 / 17$ & -5.76 & 31.8 \\
\hline $7 / 24 / 17$ & -4.0 & 31.7 \\
\hline $11 / 6 / 17$ & -3.39 & 16.3 \\
\hline
\end{tabular}

-3.13 (Fig. 1). Since starting GH replacement therapy, and normalization of thyroid hormone levels with adequate levothyroxine replacement her hemoglobin has improved and is now normal. She has not required a transfusion in the past year. At 4 years of age, the baseline cortisol was again low and she was recently started on hydrocortisone.

She has been also diagnosed with bilateral mild sensorineural hearing loss, for which she is being followed by ENT and is scheduled to get a hearing aid. Ophthalmology is following her for alternating exotropia and moderate astigmatism.

Due to long-standing untreated congenital hypothyroidism and hypopituitarism she has severe global development delay and is currently getting physical, occupational and speech therapies. Currently, at

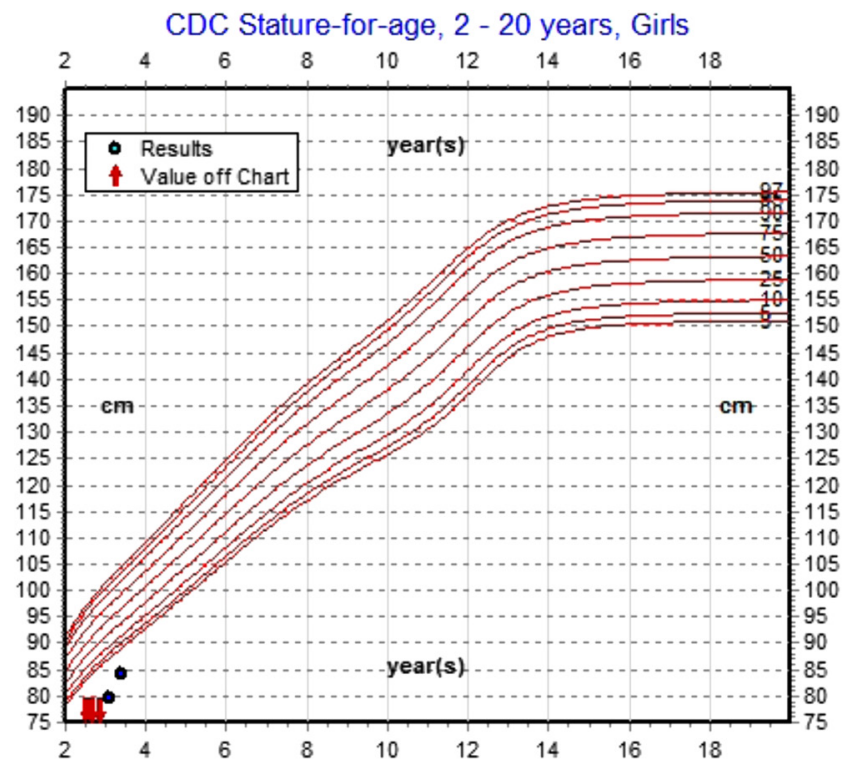

Figure 1

Height points and improvement after start of growth hormone. 
Table 3 LHX3 mutations with limited neck mobility and sensorineural hearing loss phenotype.

\begin{tabular}{|c|c|}
\hline Mutation/AA change & Type \\
\hline c. $95-2 A>G$ & Splice site \\
\hline c. 111 delT p.Gly38Alafs* 140 & Deletion \\
\hline c. $148 \mathrm{~A}>\mathrm{T}$ p.Lys50Ter & Nonsense \\
\hline c. 229 C $>$ T p.Arg77Ter & Nonsense \\
\hline c.302-303delGcinsTCCT p.Gly101Valfs*78 & Deletion \\
\hline c.347A>G p.Tyr116Cys & Missense \\
\hline c. $368 \mathrm{G}>8$ p.Cys $123 \mathrm{Tyr}$ & Missense \\
\hline c.437G > T p.Cys146Phe & Missense \\
\hline c.466C>T p.Arg156Ter & Nonsense \\
\hline c. $581 \mathrm{~A}>\mathrm{G}$ p.Gln194Arg & Missense \\
\hline c.644C>T p.Ala215Val & Missense \\
\hline C687G >A p.Trp229Ter & Nonsense \\
\hline$C 267-3 C>G$ & Splicing \\
\hline c. $4702 \mathrm{~A}>\mathrm{G}$ & Splicing \\
\hline$<1.4 \mathrm{Mb}$ including entire gene & Gross deletion \\
\hline $23 b p$ E313-3 to E313+20 & Gross deletion \\
\hline 3088 bp incl. ex. $2-5$ & Gross deletion \\
\hline
\end{tabular}

4 years of age, she is not able to sit or stand by herself, she can only say a few words and does not roll over.

\section{Discussion}

The Syrian war has been especially devastating to the embattled nation's children. The health impact of war on Syrian children is significant with infectious disease and malnutrition having the largest public health impact. Syrian children with congenital disorders clearly also suffer from a lack of early timely diagnosis, continuity, access to specialist care, access to medications and advanced diagnostic tools which lead to severe developmental delays (7). Our case illustrates the lifelong impact of war on a Syrian child and her family, due to a delay in appropriate medical care, for congenital pituitary hormone deficiencies.

A complex series of developmental steps must occur in the pituitary gland in a temporally and spatially specific manner in order for normal pituitary structure and function to develop. CPHD refers to a rare group of disorders in which at least two anterior pituitary hormone deficiencies are present in an individual. CPHD has a variable phenotypic presentation linked to several abnormal genes encoding signaling molecules and transcription factors. Pituitary transcription factors such as POU1F1, PROP1, LHX3, LHX4, OTX2, SOX2, GLI2 and HESX1 are part of the homeobox gene family and are key in morphogenesis and organogenesis of the pituitary gland. Mutations in early transcription factors include HESX1, LHX3, LHX4, SOX3, OTX2 and late transcription factors are typically PROP1, POU1F1 (6). Mutations in early transcription factors present with extra-pituitary involvement due to their roles in early embryonic development (8). Phenotypes are variable yet specific to certain mutations. For example, septo-optic dysplasia is associated with HESX1 mutation, additionally, limited neck rotation and sensorineural hearing loss are features associated with LHX3. Poorly developed sella turcica is associated with LHX4 mutations (9). Additionally, LHX3 and LHX4 mutations are associated with Chiari I malformation, corpus callosum agenesis or hypoplasia and skeletal abnormalities (10). Specific genetic mutations in CPHD patients are not frequently identified. A 2015 review of 21 studies examining CPHD patients indicated that the worldwide frequency of mutations found in PROP1, POU1F1, HESX1, LHX 4 and LHX3 is around $12.4 \%$ (7). In this particular study, 797 patients were evaluated, and LHX 3 mutations were seen at a rate of $0.3 \%$ for sporadic cases and $11.1 \%$ of familial cases.

LHX3 protein is a transcription factor protein from the LIM-HD subfamily encoded by a gene located on chromosome 9q34.3 $(3,8)$. The human LHX3 gene contains seven coding exons and six introns on chromosome 9q34 and encodes three protein isoforms of the LHX3 transcription factor (5). Clinically LHX3 mutations have hypopituitarism affecting GH, TSH, prolactin, luteinizing hormone and follicular-stimulating hormone (3). Variable pituitary findings on imaging can be seen including hypoplasia, hyperplasia or presence of a microadenoma (6). Adrenocorticotropic hormone deficiency, cervical abnormalities with or without mobility impairment and sensorineural hearing loss can also be seen and also can develop gradually over time (9). A recent case series and review of the literature indicated there are now 16 published LHX3 mutations sharing a similar phenotype with limited neck mobility and varying degrees of sensorineural hearing loss $(6,9)$. Our novel mutation of LHX3 and all others are enumerated in Table 3.

Our patient initially came to medical attention in Egypt at 10 months of age due to developmental delay. She was diagnosed with central hypothyroidism when labs showed low TSH and low FT4. It is not known if she was screened for hypothyroidism at birth and if TSHbased screening was used. She received thyroid hormone replacement from that point off and on due to poor access to care. By the time she was admitted in CHOC Children's she had undetectable TSH and FT4 levels. She suffers from severe developmental delay and she receives extensive 
physical therapy, occupational therapy and speech therapy. The development delay is related to very late diagnosis of central congenital hypothyroidism. She also had classical features of GH deficiency such as extreme growth failure, frontal bossing, midfacial hypoplasia and hypertelorism. GH deficiency was not evaluated until she came to United States at 2.5 years of age. She was started on GH therapy at the starting dose of $0.3 \mathrm{mg} / \mathrm{kg} /$ week and the growth velocity increased to up to $31 \mathrm{~cm} /$ year showing catch up growth, an excellent response to GH therapy with a change in the height SDS from -7.98 to -3.13 in 2 years. The deficiency of GH was speculated to be related her aplastic type of anemia, which mimicked DBA.

This case study demonstrates the phenotypic variability in CPHD patients with mutations in LHX3. The actions of other genes within the genomes of these patients are likely to affect the phenotypic outcome of inactivating LHX3 mutations. In mice, LHX3 is expressed in several regions of the nervous system including the brainstem, pons, medulla oblongata, pineal, and hindbrain (4). Similarly, the association between LHX3 mutations and nervous system pathologies such as amyotrophies, speech difficulties and mental retardation are seen in human subjects with LHX3 mutations. Infants with CPHD can evade early detection due to TSH being normal and hypoglycemia may not be recognized or present when adrenocorticotropic hormone and GH deficiencies are present (6). In our unique case, she was diagnosed with a type of aplastic anemia specifically called DBA receiving multiple $\mathrm{RBC}$ transfusions and steroid therapy. The diagnosis was not substantiated after the move to the US The genetic testing has come back as normal and the hemoglobin has come back to the normal range since starting GH replacement therapy, and normalization of thyroid hormone levels, thus supporting chronic illness and GH deficiency as the most likely etiology for her anemia. She has not required a transfusion in the past year.

Our case represents a rare example of a CPHD patient who was untreated for the first ten months of life and sub-optimally treated for the first 2.5 years of her life. In her case, knowledge of the specific mutation has helped provide genetic counseling to parents about future pregnancies, will help guide clinical screening studies. Testing for specific mutations in CPHD patients may predict other pituitary hormone deficiencies and enable prompt diagnosis and treatment of affected siblings (6). There is a high risk of hearing deficit with $L H X 3$ mutation as described in many case reports. The available literature led to early screening and treatment for hearing deficit in our patient. This case report adds to the body of literature on LHX3 mutations and assists genetic counselors; clinicians and families understand this developing syndrome and its implications.

\section{Declaration of interest}

The authors declare that there is no conflict of interest that could be perceived as prejudicing the impartiality of this case report.

\section{Funding}

This research did not receive any specific grant from any funding agency in the public, commercial or not-for-profit sector.

\section{Patient consent}

Written informed consent has been obtained.

\section{Author contribution statement}

Dr Amrit Bhangoo was involved in care of the patient on initial presentation as well as currently in continuity. He acted as author of the manuscript and contributed to the writing of the case report. Dr Susan Ahern participated periodically in follow-up clinic visits for this patient. She contributed to writing of case report acted as author and prepared the manuscript for submission. Dr Mark Daniels was involved in the care of the patient on initial presentation. He acted as an author for this publication.

\section{References}

1 Hunter CS \& Rhodes SJ. LIM-homeodomain genes in mammalian development and human disease. Molecular Biology Reports 200532 67-77. (https://doi.org/10.1007/s11033-004-7657-z)

2 Zhadanov AB, Bertuzzi S, Taira M, Dawid IB \& Westphal H. Expression pattern of the murine LIM class homeobox gene Lhx3 in subsets of neural and neuroendocrine tissues. Developmental Dynamics 1995202 354-364. (https://doi.org/10.1002/ aja.1002020405)

3 Bhangoo AP, Hunter CS, Savage JJ, Anhalt H, Pavlakis S, Walvoord EC, Ten S \& Rhodes SJ. Clinical case seminar: a novel LHX3 mutation presenting as combined pituitary hormonal deficiency. Journal of Clinical Endocrinology and Metabolism 200691 747-753. (https://doi.org/10.1210/jc.2005-2360)

4 West BE, Parker GE, Savage JJ, Kiratipranon P, Toomey KS, Beach LR, Colvin SC, Sloop KW \& Rhodes SJ. Regulation of the folliclestimulating hormone beta gene by the LHX3 LIM-homeodomain transcription factor. Endocrinology 2004145 4866-4879. (https://doi. org/10.1210/en.2004-0598)

5 Sloop KW, Dwyer CJ, Rhodes SJ, Meier BC, Bridwell JL, Parker GE, Schiller AM, Showalter AD, Von Kap-Herr C \& Pettenati MJ. An isoform-specific inhibitory domain regulates the LHX3 LIM homeodomain factor holoprotein and the production of a functional alternate translation form differential activation of pituitary hormone genes by human Lhx3 isoforms with distinct DNA 
binding properties. Analysis of the human LHX3 neuroendocrine transcription factor gene and mapping to the subtelomeric region of chromosome 9. Journal of Biological Chemistry 2001276 36311-36319. (https://doi.org/10.1074/jbc.M103888200)

6 De Rienzo F, Mellone S, Bellone S, Babu D, Fusco I, Prodam F, Petri A, Muniswamy R, De Luca F, Salerno M, et al. Frequency of genetic defects in combined pituitary hormone deficiency: a systematic review and analysis of a multicentre Italian cohort. Clinical Endocrinology 201583 849-860. (https://doi.org/10.1111/ cen.12849)

7 Meiquari L, Hoetjes M, Baxter L \& Lenglet A. Impact of war on child health in northern Syria: the experience of Medecins Sans Frontieres. European Journal of Pediatrics 2018177 371-380. (https://doi. org/10.1007/s00431-017-3057-y)
8 Giordano M. Genetic causes of isolated and combined pituitary hormone deficiency. Best Practice and Research: Clinical Endocrinology and Metabolism 201630 679-691. (https://doi.org/10.1016/j. beem.2016.09.005)

9 Kristrom B, Zdunek AM, Rydh A, Jonsson H, Sehlin P \& Escher SA. A novel mutation in the LIM homeobox 3 gene is responsible for combined pituitary hormone deficiency, hearing impairment, and vertebral malformations. Journal of Clinical Endocrinology and Metabolism 200994 1154-1161. (https://doi.org/10.1210/jc.2008-0325)

10 Choi JH, Jung CW, Kang E, Kim YM, Heo SH, Lee BH, Kim GH \& Yoo HW. Rare frequency of mutations in pituitary transcription factor genes in combined pituitary hormone or isolated growth hormone deficiencies in Korea. Yonsei Medical Journal $2017 \mathbf{5 8}$ 527-532. (https://doi.org/10.3349/ymj.2017.58.3.527)

Received in final form 10 October 2018 Accepted 30 October 2018 